\title{
Development and validation of the Neonatal Mortality Score-9 Mexico to predict mortality in critically ill neonates
}

\author{
Horacio Márquez-González, M. Sc. ${ }^{a}$, María Valeria Jiménez-Báez, $M D^{b}$, \\ C. Mireya Muñoz-Ramírez, M. Sc. ${ }^{c}$ Lucelli Yáñez-Gutiérrez, M. Sc. ${ }^{a}$, \\ Ana C. Huelgas-Plaza, $M D^{d}$, Eduardo Almeida-Gutiérrez, $M D^{e}$, and \\ Antonio Rafael Villa-Romero, $M D^{f}$
}

\begin{abstract}
Introduction. Prognostic scales or scores are useful for physicians who work in neonatal intensive care units. There are several validated neonatal scores but they are mostly applicable to low birth weight infants. The aim of this study was to develop and validate a mortality prognostic score in newborn infants, that would include new prognostic outcome measures.

Population and Methods. The study was conducted in a mother and child hospital in the city of Mexico, part of the Instituto Mexicano del Seguro Social (Mexican Institute of Social Security). In the first phase of the study, a nested case-control study was designed (newborn infants admitted on the basis of severity criteria during the first day of life), in which a scale was identified and developed with gradual parameters of cumulative score consisting of nine independent outcome measures to predict death, as follows: weight, metabolic acidemia, lactate, $\mathrm{PaO}_{2} / \mathrm{FiO}_{2}, \mathrm{p}(\mathrm{A}-\mathrm{a}) \mathrm{O}_{2}, \mathrm{~A} / \mathrm{a}$, platelets and serum glucose.Validation was performed in a matched prospective cohort, using 7-day mortality as an endpoint.

Results. The initial cohort consisted of 424 newborn infants. Twenty-two cases and 132 controls were selected; and 9 outcome measures were identified, making up the scale named neonatal mortality score-9Mexico. The validation cohort consisted of 227 newborn infants. Fortyfour $(19 \%)$ deaths were recorded, with an area under the curve (AUC) of 0.92. With a score between 16 and 18, an 85 (11-102) hazard ratio, $99 \%$ specificity, $71 \%$ positive predictive value and $90 \%$ negative predictive value were reported. Conclusions. The proposed scale is a reliable tool to predict severity in newborn infants.

Key words: child mortality, neonatal intensive care units, risk factors, disease severity index.
\end{abstract}

http:/ /dx.doi.org/10.5546/aap.2015.eng.213

M.

M. Sc. Horacio

Márquez-González:

horacioinvestigacion@

hotmail.com

Funding:

None.

Conflict of Interest:

None.

Received: 9-19-2014

Accepted: 1-5-2015 and sepsis. ${ }^{2}$ Intervention through preventive measures has managed to reduce up to $67 \%$ of neonatal mortality. ${ }^{3}$

In Mexico, ${ }^{4} 2271700$ deaths were registered in 2003; 20806 of those deaths occurred during the neonatal period; $49.4 \%$ of them were associated to asphyxia.

Detection of critically ill newborn infants offers the possibility of a timely treatment that would have a direct impact on survival and decrease morbidity. Prognostic scales are useful for physicians working in neonatal intensive care units (NICUs). There are scales or scores used at an international level: ${ }^{5} \mathrm{SNAPPE}^{6}$ (Score for Neonatal Acute Physiology Perinatal Extension), CRIB II (Clinical Risk Index for Babies Score) and NEOCOSUR (Neonatal del Cono Sur). ${ }^{8}$ They are mostly used in premature infants weighing under $1500 \mathrm{~g}$.

This study proposes the development and validation of a score to predict mortality in critically ill newborn infants, without excluding those weighing above $1500 \mathrm{~g}$, based on the inclusion of new prognostic factors.

\section{POPULATION AND METHODS}

With the authorization of the local institutional review board (R-2012-6790-89), the study was conducted in Hospital General of Zona 2 A Troncoso, from the Instituto Mexicano del Seguro Social (IMSS), and comprised the following phases:

a) Identification of possible predictive outcome measures: From January 2005 to December 2010, a cohort was prospectively defined inclu- 
ding newborn infants of any gestational age, both genders, multiple gestations and visible external malformations. They had to be delivered at the Obstetrical-Surgery Unit of the Hospital, admitted at the NICU on their first day of life and under care until discharged for any cause. Patients born in other units were excluded and newborn infants voluntarily withdrawn by their parents or transferred to other hospitals were removed. The sample size calculation was based on the previous year statistics, with a total of 3450 births and 11\% mortality, $a=95 \%$ and $d=99 \%$ (0.001), replaced in the odds ratio formula for finite population, ${ }^{9}$ with an estimate patient number of 204 . A $10 \%$ was added to make up for estimated losses, resulting in a final calculation of 224 patients.

b) Association with the outcome measure: Several prenatal outcome measures were investigated: threatened preterm labor, prenatal infections, diabetes, preeclampsia, premature rupture of membranes and prenatal administration of steroids. Perinatal outcome measures were: Apgar and Silverman-Andersen score at one and five minutes, gestational age by Capurro in newborn infants older than 32 weeks of gestational age and Ballard score in those under 28 weeks of gestational age, weight for gestational age, as well as outcome measures upon admission at the NICU as follows: blood gases, blood count and blood chemistry determined during the first hour, ventilation parameters: $\mathrm{p}(\mathrm{A}-\mathrm{a}) \mathrm{O}_{2}, \mathrm{paO}_{2} / \mathrm{FiO}_{2}, \mathrm{~A} / \mathrm{a}$. The time of admission at the NICU was considered as baseline.The endpoint was 7-day mortality rate.

Patients who died up to day 7 were considered "cases", and all patients remaining alive up to this timepoint were considered "controls". Six controls were randomly selected per each case (using the Aleator Method software for Excel).

c) Assessment of prediction capacity using an independent model: A univariate association of risk variables was conducted, and those found to be significant were subjected to a logistic regression analysis. Nine independent outcome measures were identified (weight, Apgar at five minutes, metabolic acidemia, lactate, alveolar-arterial gradient and ratio, Kirby index and glucose).

d) Development of the scale scoring system: Outcome measures resulting from the final model were scored based on the significance of the statistical association reported by other authors (prognosis and meta-analysis articles)..$^{10-18}$ Results obtained were compared to those from the first cohort: values reported as normal and within the median were considered as 0 points; values corresponding to the 3rd quartile, 1 point; and the value from the last quartile, 2 points (Table 1). The scale was named Neonatal Mortality Score-9 Mexico (EMN-9 Mex).

e) Calculation of the diagnostic accuracy of the scale: individual scores were added up and a ROC curve was developed to determine the best cut-off point and to calculate the area under the curve. Stratification was chosen using the items corresponding to values of 1 sensitivity of the following ranges: $<0.5 ; 0.51$ $0.75 ; 0.76-0.94$ and $\geq 0.95$.

f) Prospective validation of the scale: A prospective cohort of newborn infants was designed using data from January 2010 to December 2012. Selection criteria were the same as for the previous cohort. Follow up started at the time newborn infants were admitted at the NICU. Outcome measures included in this scale were taken within the first hour of admission Based on the first phase of the study that included 424 patients admitted in the NICU, with a 5\% mortality rate $(a=95 \%$ and $d=99 \%)$, the odds ratio for a finite population was estimated resulting in a required sample size of 90 newborn infants. A $10 \%$ was added for losses and 10 patients were added per outcome measure (90), resulting in a final size of 189 patients.

Statistical analysis: for the descriptive statistics central trends (s median) and scatter (interquartile ranges) were used for quantitative outcome measures, and frequencies and percentages were used for qualitative outcome measures. In the first cohort, the risk by odds ratio (OR) was calculated and a logistic regression analysis was performed. For the second cohort, a Cox analysis was carried out and the hazard ratio (HR) was calculated; survival analysis by Kaplan Meier and validity tests (sensitivity, specificity, predictive values, likelihood values and area under the curve) were performed for each of the strata proposed.

The Statistical Package for the Social Sciences (SPSS), version 20 for Windows was used in the statistical package. 


\section{RESULTS}

First cohort: 424 newborn infants met the eligibility criteria. Twenty-two cases were presented and 132 controls were randomly selected (Figure 1.A). Differences between cases and controls, as well as risk calculation and adjustment are shown in Table 2.

Second cohort: During the study period, there was a total of 7300 deliveries, out of which 306 newborn infants were admitted at the NICU. Finally, 227 patients were included (Figure 1.B). On average, the early neonatal mortality rate was 8.5 newborn infants per 1000 births; 133 $(58 \%)$ were classified as very low birth weight for gestational age.

Of the participants, $140(61 \%)$ were male; the median gestational age was 33 weeks (24-39); the median weight was $1100 \mathrm{~g}$ (780-2100); and the median height was $43 \mathrm{~cm}(38-48)$. Forty-four deaths $(19 \%)$ were registered.

The score area under the curve was 0.92 , $\mathrm{p}<0.0001$, for mortality prediction; the confounder-adjusted HR of each stratum is shown in Table 3. The validity of each stratum is shown in Table 4. Cumulative survival probability by day 7 was $81 \%$. Figure 2 shows survival by scoring strata.

\section{DISCUSSION}

Scales are tools used in medical practice to predict the behavior of a disease, they signal the development of complications or death and are useful for the subsequent evaluation of healthcare programs. ${ }^{19}$

The population of the hospital where the study was conducted matches the population characteristics of most cities. Causes of death agree with epidemiology reports from Mexico and the rest of the world. ${ }^{4}$

In the first cohort, factors associated with death were identified, and results showed that independent outcome measures in the multicause model were consistent with those found by other authors; some of these were items of already validated scores. ${ }^{6}$ However, other outcome measures, such as ventilation and diffusion rates, platelets and hyperglycemia are new compared to the previously mentioned scales.

Perinatal outcome measures did not prove to be useful in our prognostic model; this phenomenon had already been contemplated by the SNAP (Score for Neonatal Acute Physiology) scale in $2001,{ }^{20}$ but ours differs from the NEOCOSUR scale ${ }^{8}$ that does include prenatal variables.

It is worth mentioning that prenatal steroid administration did not prove to be significant on the final model, which differs from reports of the NEOCOSUR group, ${ }^{8}$ probably because the population is not held at the study center and the time necessary to artificially induce lung maturation is not enough.

Prematurity is the main comorbidity associated with death and it is represented in our scale by birth weight (due to the likelihood of multi-co-linearity, it was managed this way in our score), given the known relationship between low birth weight and mortality. ${ }^{21,22} \mathrm{We}$ consider this finding is timely taking into account that estimating gestational age may not be so

TABLE 1. Scale to predict mortality in critically ill newborn infants (EMN - 9 Mex)

\begin{tabular}{|c|c|c|c|}
\hline \multirow[t]{2}{*}{ Outcome measure } & \multicolumn{3}{|c|}{ Score } \\
\hline & 0 & 1 & 2 \\
\hline Apgar score at five minutes (points) & From 9 to 10 & From 7 to 8 & $\leq 6$ \\
\hline Birthweight (g) & $\geq 2500$ & From 1500 to 2499 & $\leq 1499$ \\
\hline Blood gases* & Normal & Metabolic acidosis & $\begin{array}{c}\text { Metabolic } \\
\text { acidosis } \\
\text { of } \mathrm{AG}^{* *} \geq 15\end{array}$ \\
\hline Lactate (mmol/L) & $\leq 1$ & $1.1-3.9$ & $\geq 4$ \\
\hline $\mathrm{PaO}_{2} / \mathrm{FiO}_{2}(\mathrm{~mm} / \mathrm{Hg})$ & $\geq 350$ & From 200 to 349 & $\leq 199$ \\
\hline $\mathrm{P}(\mathrm{A}-\mathrm{a}) \mathrm{O}_{2}(\mathrm{~mm} / \mathrm{Hg})$ & $\geq 100$ & $101-299$ & $\geq 300$ \\
\hline $\mathrm{A} / \mathrm{a}$ & $\geq 0.6$ & $0.5-0.26$ & $\leq 0.25$ \\
\hline Platelets $($ cell $/ \mu \mathrm{L})$ & $\geq 150000$ & $50000-149000$ & $\leq 50000$ \\
\hline Serum glucose (mg/dL) & $\leq 126 \mathrm{mg} / \mathrm{dL}$ & From 127 to $200 \mathrm{mg} / \mathrm{dL}$ & $\geq 201 \mathrm{mg} / \mathrm{dL}$ \\
\hline
\end{tabular}

* Acidosis: $\mathrm{pH} \leq 7.28$ and base excess below $6 \mathrm{mmol} / \mathrm{L}$.

** Anion gap (AG): $\mathrm{Na}-\left(\mathrm{HCO}_{3}+\mathrm{Cl}\right)$. 
reliable to indicate prematurity considering all the chances of variability in the interpretation of rating tools, even among pediatricians. ${ }^{23}$

Perinatal asphyxia is one the main causes of death and it is biologically plausible that a low Apgar score and metabolic acidemia are part of the scale. ${ }^{24}$ Respiratory disorders, such as respiratory distress syndrome, intrauterine pneumonia or meconium aspiration syndrome are the main comorbidities and their severity affects oxygen diffusion in different degrees. $\mathrm{PaO}_{2} / \mathrm{FiO}_{2}$ ratio infers lung damage, whilst $\mathrm{p}(\mathrm{A}-\mathrm{a})$ $\mathrm{O}_{2}$ considers the difference between alveolar and capillary oxygen, and A/a shows the same

FIGURE 1. Selection scheme of the first cohort $(A)$ and the second cohort $(B)$ subjects

A

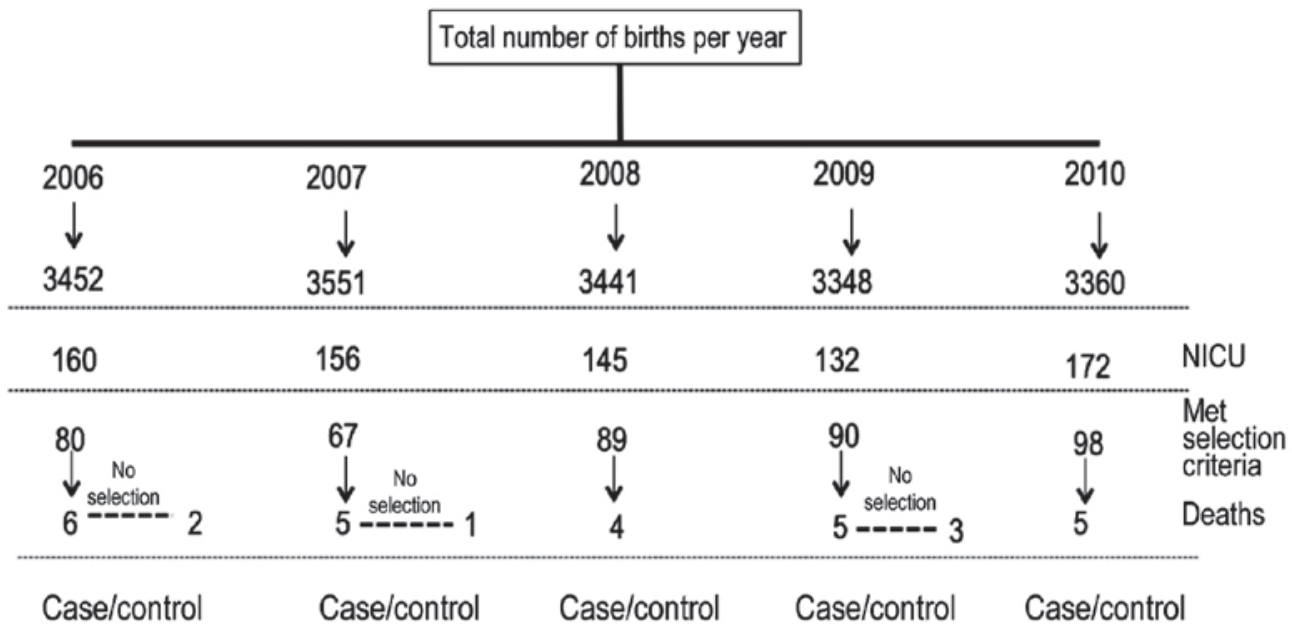

$4 / 24$

$4 / 24$

$4 / 24$

$5 / 30$

$5 / 30$

Total

22 cases and 132 controls

B

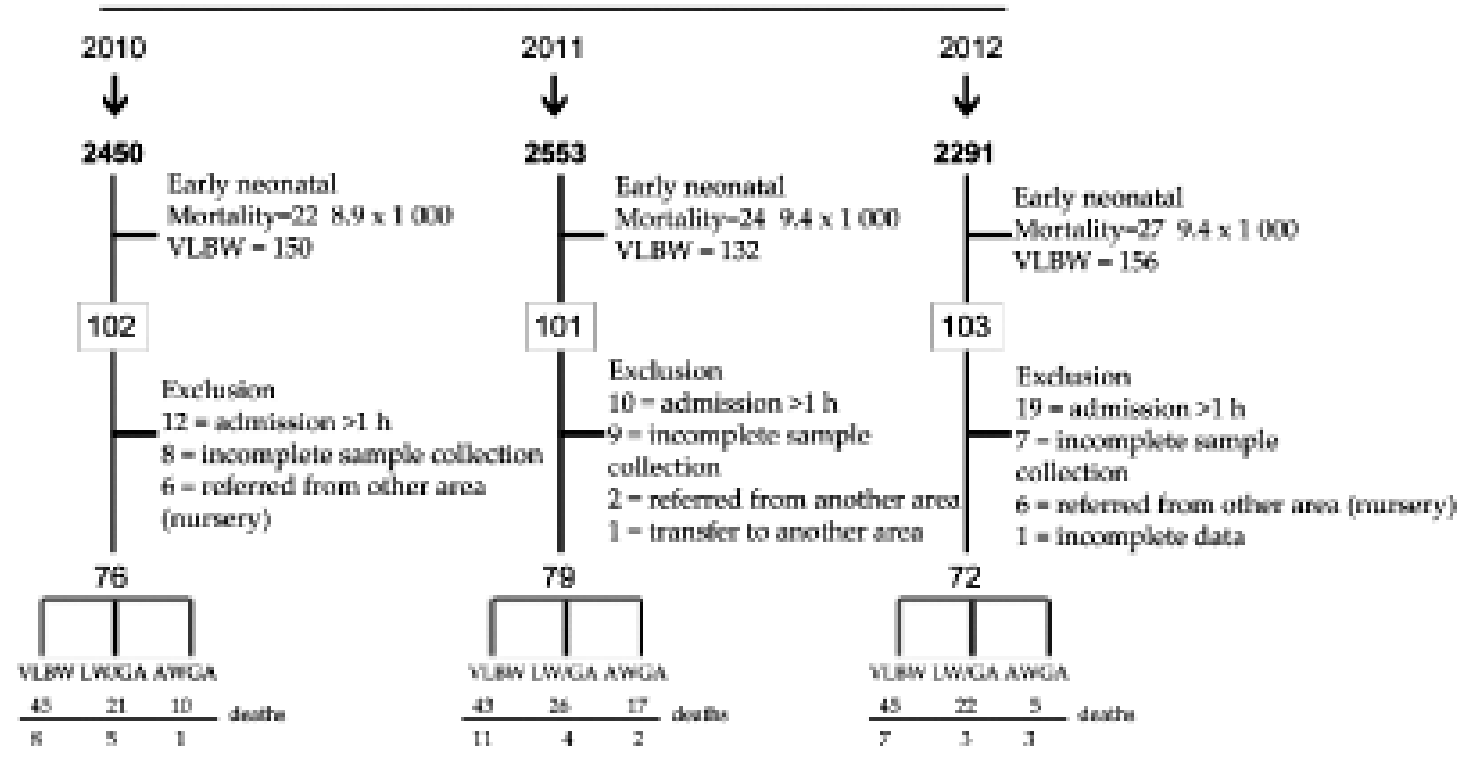

CS: met selection criteria. VLBW: very low birth weight. AWGA: appropriate weight for gestational age. LW/GA: low weight for gestational age. NICU: Neonatal Intensive Care Units. 
phenomenon without estimating the $\mathrm{FiO}_{2}$ effect. ${ }^{26}$ The result from both formulas points at a disorder at the alveolar-capillary membrane level.

Hypoperfusion states alter lactate and glucose levels ${ }^{27}$ and platelet function. ${ }^{28}$ Taking into account that most neonatal comorbidities impair tissue oxygen diffusion, it is reasonable that they remain as independent variables and form part of the scale.

None of the previously published scales or scores include hyperglycemia as a mortalityrelated factor. Glucose levels are increased because there is an immaturity in insulin secretion and are associated with conditions that cause death, such as intraventricular hemorrhage, sepsis, necrotizing enterocolitis, among others. ${ }^{30}$

The validation cohort of EMN-9 Mex was consistent with the group of patients of the original cohort, in which items constituting this scale arose. All the outcome measures included in the scale kept their significance.

Most mortality scales use coefficients to determine the predictive weight of their variables. It is difficult to substitute such values in daily practice; for this reason we considered that the development and interpretation of the EMN9 Mex had to be easy, based on simply adding up points to obtain a score because users are

TABLE 2. First phase results: comparison of risk factors between live and dead newborn infants

\begin{tabular}{|c|c|c|c|c|}
\hline Outcome measure & Live $n=132$ & Dead $n=22$ & $\begin{array}{c}\text { OR (CI 95\%) } \\
\text { raw }\end{array}$ & $\begin{array}{c}\text { OR (CI 95\%) } \\
\text { adjusted }\end{array}$ \\
\hline Preeclampsia & $21(16 \%)$ & $3(13 \%)$ & $0.7(0.1-3.7)$ & $0.8(0.3-19)$ \\
\hline Gestational diabetes & $22(17 \%)$ & $6(25 \%)$ & $1.4(0.5-6)$ & $2(0.3-23)$ \\
\hline External malformations & $16(12 \%)$ & $4(20 \%)$ & $1.7(0.9-7)$ & $2.4(0.7-15)$ \\
\hline Threatened preterm labor & $9(7 \%)$ & $1(5 \%)$ & $0.8(0.09-6.9)$ & $0.4(0.2-5)$ \\
\hline Multiple pregnancy & $8(6 \%)$ & $1(5 \%)$ & $0.8(0.7-1.3)$ & $0.4(0.3-8)$ \\
\hline Third trimester infections & $21(16 \%)$ & $3(13 \%)$ & $0.7(0.1-3)$ & $0.8(0.5-13)$ \\
\hline Premature rupture of membranes $>8 \mathrm{~h}$ & $25(19 \%)$ & $7(32 \%)$ & $1.7(0.5-5.8)$ & $1.3(0.4-14)$ \\
\hline Prenatal steroids & $22(17 \%)$ & $1(5 \%)$ & $0.8(0.7-0.9)$ & $0.6(0.1-1.1)$ \\
\hline Apgar $<6$ at one minute & $46(35 \%)$ & $15(70 \%)$ & $4(1.3-12)$ & $1.4(0.8-14)$ \\
\hline Apgar $<6$ at five minutes & $12(9 \%)$ & $8(38 \%)$ & $5.9(1.8-19)$ & $3.5(1.7-5)$ \\
\hline $\mathrm{SA}>3$ at one minute & $30(23 \%)$ & $11(50 \%)$ & $3.1(1.1-9.2)$ & $14(0.4-20)$ \\
\hline $\mathrm{SA}>3$ at five minutes & $67(51 \%)$ & $15(69 \%)$ & $2(0.6-6.2)$ & $3(0.2-7)$ \\
\hline \multicolumn{5}{|l|}{ Gestational age } \\
\hline$>37$ weeks & $93(70 \%)$ & $4(18 \%)$ & $0.03(0.01-0.7)$ & - \\
\hline 32-36.6 weeks & $30(23 \%)$ & $11(50 \%)$ & $2.3(1.2-7)$ & $1.2(0.4-1.9)$ \\
\hline$<31.6$ weeks & $9(7 \%)$ & $7(32 \%)$ & $3.1(1.7-8.9)$ & $1.5(0.9-12)$ \\
\hline \multicolumn{5}{|l|}{ Weight $(\mathrm{g})$} \\
\hline$>2500$ & $86(65 \%)$ & $5(22 \%)$ & $0.4(0.1-0.7)$ & - \\
\hline $1500-2499$ & $33(25 \%)$ & $7(33 \%)$ & $2.4(1.3-6.5)$ & - \\
\hline$<1499$ & $13(10 \%)$ & $10(45 \%)$ & $5(2.3-8)$ & $4.3(2-5.4)$ \\
\hline \multicolumn{5}{|l|}{ Gender } \\
\hline Male & $53(40 \%)$ & $8(37 \%)$ & $1.01(0.9-1.1)$ & - \\
\hline Female & $79(60 \%)$ & $14(63 \%)$ & $0.9(0.3-2.2)$ & $0.5(0.3-13)$ \\
\hline Metabolic acidemia & $72(55 \%)$ & $20(91 \%)$ & $1.5(1.2-9)$ & $1.7(1.2-3.2)$ \\
\hline Elevated anion gap (> 15) & $46(35 \%)$ & $31(70 \%)$ & $6(2-10)$ & $2.8(1.5-5.8)$ \\
\hline Lactate $>4 \mathrm{mmol} / \mathrm{L}$ & $33(25 \%)$ & $20(91 \%)$ & $23(6-310)$ & $12(3-17)$ \\
\hline Hemoglobin $<9 \mathrm{~g} / \mathrm{dL}$ & $5(4 \%)$ & $2(10 \%)$ & $1.3(0.6-5)$ & $1.1(0.5-1.5)$ \\
\hline Platelets $<100000$ cell $/ \mu \mathrm{L}$ & $9(7 \%)$ & $7(32 \%)$ & $5.4(1.5-18)$ & $2.9(2-4.3)$ \\
\hline $\mathrm{A} / \mathrm{a}<0.23$ & $66(50 \%)$ & $20(91 \%)$ & $1.7(1.1-1.5)$ & $1.3(1.1-2)$ \\
\hline $\mathrm{P}(\mathrm{A}-\mathrm{a}) \mathrm{O}_{2}$ & $59(45 \%)$ & $21(95 \%)$ & $1.8(1.2-2)$ & $1.4(1.2-3)$ \\
\hline $\mathrm{paO}_{2} / \mathrm{FiO}_{2}^{2}<200$ & $106(80 \%)$ & $21(95 \%)$ & $1.8(1.1-2.1)$ & $2.2(1.3-4)$ \\
\hline Hyperglycemia & $26(20 \%)$ & $11(50 \%)$ & $4(1.3-11)$ & $2.4(1.7-3.6)$ \\
\hline Hiperglucemia & $26(20 \%)$ & $11(50 \%)$ & $4(1,3-11)$ & $2,4(1,7-3,6)$ \\
\hline
\end{tabular}

Hyperglycemia: levels above $126 \mathrm{mg} / \mathrm{dL}$ in term newborn infants and $180 \mathrm{mg} / \mathrm{dL}$ in premature patients. External malformations: it refers to major alterations, such as midline malformations, congenital heart disease and severe cyanosis, head deformities or any other visible malformation involving vital functions.

Alveolar-arterial oxygen gradient: $\mathrm{p}(\mathrm{A}-\mathrm{a}) \mathrm{O}_{2}$.

Alveolar-arterial ratio: $\mathrm{pAO}_{2} / \mathrm{paO}_{2}\left(\mathrm{pAO}_{2}\right.$ or arterial oxygen partial pressure: $\left.\left(\mathrm{PB}_{-} \mathrm{PH}_{2} \mathrm{O}\right) \times \mathrm{FiO}_{2}-\left(\mathrm{PaCO}_{2} / 0.8\right) \times 1.25\right)$.

* The dash (-) represents the category of reference.

SA: Silverman Andersen score. 
accustomed to similar scales such as the Apgar Score. $^{31}$

The SNAP and SNAPPE scales are the most widely used. In their first version, they included a wide range of outcome measures that complicated their implementation, which led to a re-edition in 2001: SNAP-II and SNAPPE II. ${ }^{8}$ The latter, unlike our score, was used in 25429 newborn infants in four hospital facilities, with an area under the curve of 0.91, excluding newborn infants seen at the NICU.

The second version of $\mathrm{CRIB}^{32}$ was developed following the release of surfactant use. It included newborn infants admitted at intensive care units,

TABLE 3. Stratified analysis of the scale scoring: risk, adjusted risk and survival probability

\begin{tabular}{|c|c|c|c|c|}
\hline Outcome measure & Live 183 & Dead 44 & HR (CI 95\%)* & p-value \\
\hline Prenatal steroids & $82(45 \%)$ & $17(39 \%)$ & $0.7(0.1-2.5)$ & 0.6 \\
\hline \multicolumn{5}{|c|}{ Apgar score at five minutes } \\
\hline $9-10$ & $90(49 \%)$ & $6(13 \%)$ & - & \\
\hline $7-8$ & $77(42 \%)$ & $22(50 \%)$ & $1.3(0.4-13)$ & 0.3 \\
\hline$<6$ & $16(9 \%)$ & $16(37 \%)$ & $2.7(1.4-5.2)$ & 0.05 \\
\hline \multicolumn{5}{|l|}{ Birthweight (g) } \\
\hline$>2500$ & $49(27 \%)$ & $8(18 \%)$ & - & \\
\hline $1500-2499$ & $86(47 \%)$ & $11(25 \%)$ & $0.8(0.4-2)$ & 0.4 \\
\hline$<1499$ & $48(26 \%)$ & $25(56 \%)$ & $4.7(1.2-9)$ & 0.01 \\
\hline \multicolumn{5}{|l|}{ Lactate $(\mathrm{mmol} / \mathrm{L}$} \\
\hline$<1$ & $99(54 \%)$ & $3(7 \%)$ & - & \\
\hline $1.1-3.9$ & $38(21 \%)$ & $7(15 \%)$ & $0.4(0.1-3)$ & 0.6 \\
\hline$>4$ & $46(25 \%)$ & $34(78 \%)$ & $5.6(1.2-7)$ & 0.03 \\
\hline \multicolumn{5}{|l|}{$\mathrm{a} / \mathrm{A}$} \\
\hline$>0.6$ & $48(26 \%)$ & $2(5 \%)$ & - & \\
\hline $0.59-0.26$ & $16(9 \%)$ & $9(20 \%)$ & $1.2(0.7-1.7)$ & 0.07 \\
\hline$<0.25$ & $19(65 \%)$ & $33(75 \%)$ & $1.8(0.9-4)$ & 0.06 \\
\hline \multicolumn{5}{|l|}{$\mathrm{P}\left(\mathrm{Ao}_{2}-\mathrm{aO}_{2}\right)$} \\
\hline$<100$ & $9(5 \%)$ & $2(5 \%)$ & - & \\
\hline $100-299$ & $165(90 \%)$ & $8(18 \%)$ & $0.2(0.01-0.7)$ & 0.05 \\
\hline$>300$ & $9(5 \%)$ & $34(77 \%)$ & $2.5(1.5-10)$ & 0.001 \\
\hline \multicolumn{5}{|l|}{ Platelets (cell $/ \mu \mathrm{L})$} \\
\hline$>150000$ & $143(78 \%)$ & $5(12 \%)$ & - & \\
\hline $50000-149000$ & $35(19 \%)$ & $17(38 \%)$ & $1.6(0.4-15)$ & 0.7 \\
\hline$<49000$ & $5(3 \%)$ & $22(50 \%)$ & $6.3(2-17)$ & 0.001 \\
\hline \multicolumn{5}{|c|}{ Serum glucose $(\mathrm{mg} / \mathrm{dL})$} \\
\hline$<126$ & $114(62 \%)$ & $8(19 \%)$ & - & \\
\hline $127-200$ & $40(22 \%)$ & $25(56 \%)$ & $2.3(1.2-6)$ & 0.05 \\
\hline$>201$ & $29(16 \%)$ & $11(25 \%)$ & $1.2(0.7-13)$ & 0.4 \\
\hline \multicolumn{5}{|l|}{ EMN-9 Mex Score } \\
\hline From 1 to 7 & $50(27 \%)$ & $1(2 \%)$ & - & - \\
\hline From 8 to 11 & $80(44 \%)$ & $4(10 \%)$ & $2.4(0.2-21)$ & 0.4 \\
\hline From 12 to 15 & $46(25 \%)$ & $22(50 \%)$ & $18(2.4-133)$ & 0.005 \\
\hline From 16 to 18 & $7(4 \%)$ & $17(38 \%)$ & $85(11-102)$ & $<0.0001$ \\
\hline
\end{tabular}

* The dash (-) represents the category of reference.

HR: hazard ratio.

TABle 4. Validity of the Neonatal Mortality Score-9 Mexico divided into four categories

\begin{tabular}{lccccccc}
\hline Score & Sensitivity & Specificity & +PV & -PV & +LR & -LR & AUC \\
\hline From 1 to 7 & $2 \%$ & $73 \%$ & $2 \%$ & $76 \%$ & $0.08(0.01-0.5)$ & $1.34(1.22-1.49)$ & $0.50(0.1-0.7)$ \\
From 8 to 11 & $9 \%$ & $56 \%$ & $5 \%$ & $72 \%$ & $0.21(1.3-1.8)$ & $1.6(1.4-1.7)$ & $0.75(0.63-0.89)$ \\
From 12 to 15 & $50 \%$ & $75 \%$ & $32 \%$ & $86 \%$ & $1.9(1.4-2.8)$ & $0.67(0.5-0.9)$ & $0.92(0.88-0.94)$ \\
From 16 to 18 & $40 \%$ & $99 \%$ & $71 \%$ & $90 \%$ & $10(4.3-23)$ & $0.6(0.4-0.8)$ & $0.95(0.9-0.97)$ \\
\hline
\end{tabular}

PV: predictive value.

LR: likelihood ratio.

AUC: area under the curve. 
but it is designed for patients weighing less than $1500 \mathrm{~g}$, as against our score that took into account newborns of any weight. The CRIB II has been used in different hospitals and it reported an area under the curve of between 0.86 and $0.9 .{ }^{33}$

A scale developed using a methodology similar to ours was published in Mexico in 2001. ${ }^{34}$ However, the newborn infants used to validate the data were gathered from three referral centers of our country where deliveries are not assisted, so the initial approach might have changed the outcome of subjects included in the study. These conditions affect the external validity of that scale; besides, outcome measures as sepsis and heart failure may vary in their identification depending on who rates them. The interpretation of this scale is based on substituting the $\beta$ coefficient of each outcome measure in the logistic regression formula, a fact that may delay and complicate its implementation in daily clinical practice. It presents an area under the curve of 0.86 and there are no other publications mentioning to have used it or validated it.

The NEOCOSUR Scale that was developed as a result of a multicenter effort in Latin American countries was validated in a population of over 1800 very low weight newborn infants using six prognostic outcome measures (weight, gestational age, Apgar score at one minute, congenital malformations, prenatal use of steroids and maternal age) with an area under the curve of 0.85 , with the advantage of being useful for other outcomes besides mortality, such as bronchopulmonary dysplasia and intraventricular hemorrhage. ${ }^{35}$ Compared to other scales or scores, it has a stronger mortality predictive power. ${ }^{8}$

Therefore, the EMN-9 Mex is a mortality predictive scale that is easy to implement and interpret, which can be used in newborn infants regardless of their birth weight, and which introduces other outcome measures that have not been used in other scales or scores.

Its weaknesses lie in the fact that the sample size and the target population are restricted to a single center while treatment approach is limited to the institution's resources. Newborn infants selected were exclusively seen at the Intensive Care Unit and the prognostic power of our score is limited to mortality in the early neonatal stage.

\section{CONCLUSIONS}

The EMN-9 Mex is a novel proposal validated for newborn infants of all weights, supported in outcome measures covering a

FIGURE 2. Survival curve by category according to the Neonatal Mortality Score-9 Mexico (EMN-9 Mex)

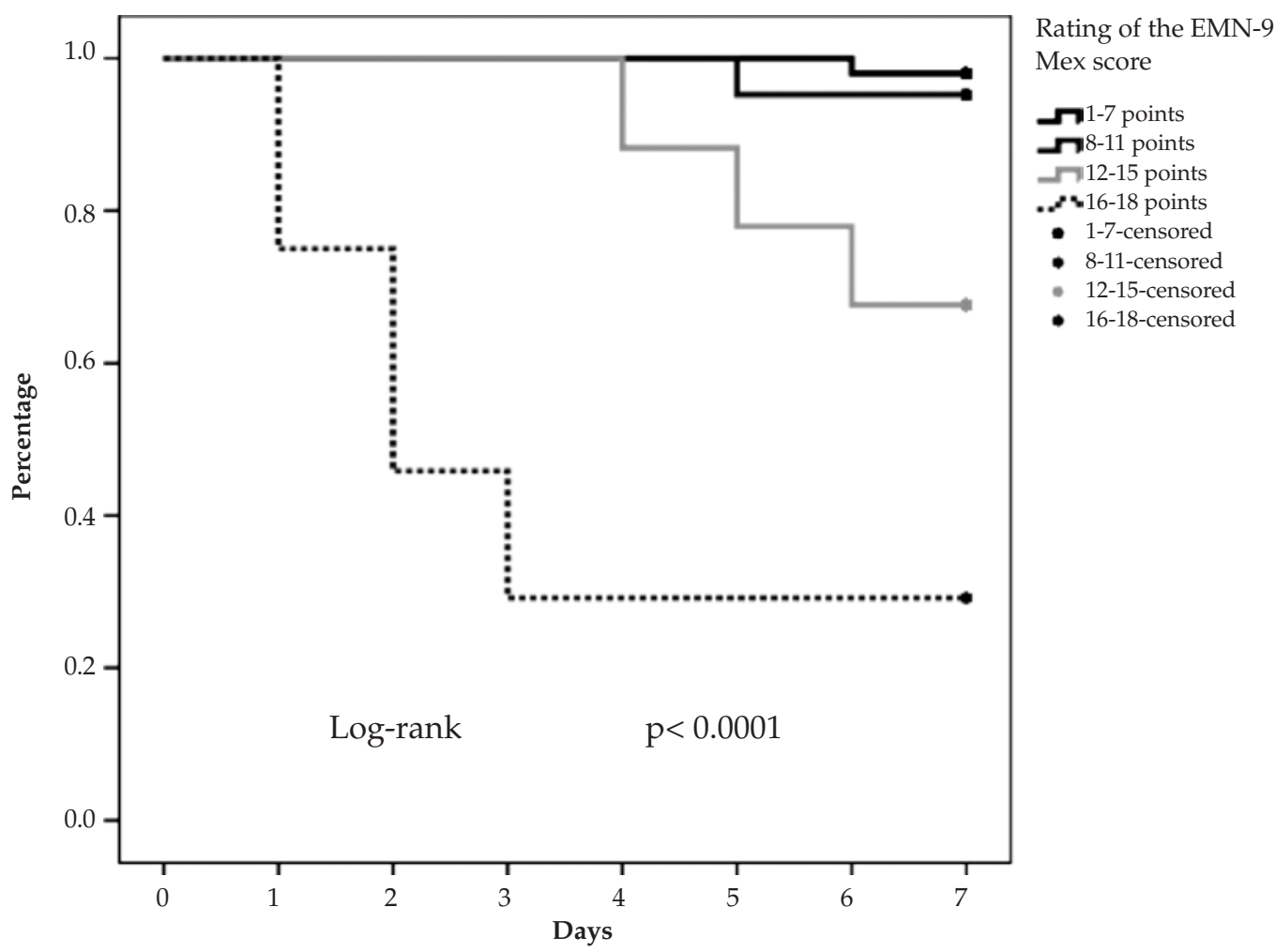


wide spectrum of diseases that lead to neonatal mortality. It would be worth validating it in a larger neonate population in other hospital facilities to specifically check how effective it is for premature, late premature, term and postterm infants.

\section{REFERENCES}

1. Shiffman J. Issue attention in global health: the case of newborn survival. Lancet 2010;375(9730):2045-9.

2. Oestergaard MZ, Inoue M, Yoshida $S$, Mahanani WR, et al. Neonatal mortality levels for 193 countries in 2009 with trends since 1990: a systematic analysis of progress, projections, and priorities. PLoS Med 2011;8(8):e1001080.

3. Martines J,Paul VK, Bhutta ZA, Koblinsky M, etal. Neonatal survival: a call for action. Lancet 2005;365(9465):1189-97.

4. Murguía SM, Lozano R, Santos JI. Mortalidad perinatal por asfixia en México: problema prioritario de salud pública por resolver. Bol Med Hosp Infant Mex 2005;62(5):375-83.

5. Záyago-Espinosa M. Utilidad de dos escalas de gravedad como factor de predictivo de mortalidad en neonatos pretérminos. Rev Sanid Milit Mex 2006;60(4):243-7.

6. Gagliardi L, Cavazza A, Brunelli A, Battaglioli M, et al. Assessing mortality risk in very low birthweight infants: a comparison of CRIB, CRIB-II, and SNAPPE-II. Arch Dis Fetal Neonatal Ed 2004;89(5):F419-22.

7. Maier RF, Rey M, Metze BC, Obladen M. Comparison of mortality risk: a score for very low birthweight infants. Arch Dis Child Fetal Neonatal Ed 1997;76(3):F146-50.

8. Marshall G, Tapia JL, D'Apremont I, Grandi C, et al. A new score for predicting neonatal very low birth weight mortality risk in the NEOCOSURSouth American Network. J Perinatol 2005;25(9):577-82.

9. Aguilar-Barojas S. Fórmulas para el cálculo de la muestra en investigaciones de salud. Salud en Tabasco 2005;11(12):333-8

10. Casey BM, Mclntire DD, Leveno KJ. The continuing value of Apgar score for the assessment of newborn infants. $N$ Eng J Med 2001;344(7):467-71.

11. Lawn CJ, Weir FJ, McGuire W. Base administration or fluid bolus for preventing morbidity and mortality in preterm infants with metabolic acidosis. Cochrane Database Syst Rev 2005;2:CD003215.

12. García HJ, Aparicio-de la Luz S, Franco-Gutiérrez M, González-Lara D, et al. Factores pronósticos de asociados a mortalidad en recién nacidos con hernia diafragmática congénita. Gac Med Mex 2003;139(1):7-14.

13. Yasmin S, Osrin D, Paul E, Costello A. Neonatal mortality of low-birth-weight infants in Bangladesh. Bull World Health Organ 2001;79(7):608-14.

14. Kao LS, Morris BH, Lally KP, Stewart CD, et al. Hyperglycemia and morbidity and mortality in extremely low birth weight infants. J Perinatol 2006;26(12):730-6.

15. VincentJL, Yagushi A, Pradier O. Platelet function in sepsis. Crit Care Med 2002;30(5 Suppl):S313-7.

16. Fernández HG, Vieira AA, Barbosa AD. The correlation between plasma lactate concentrations and early neonatal mortality. Rev Bras Ter Intensiva 2012;24(2):184-7.

17. Mathur NB, Garg P, Mishra TK. Predictors of fatality in neonates requiring mechanical ventilation. Indian Pediatr 2005;42(7):645-51.
18. Dimitriou G, Fouzas S, Giannakopoulos I, Papadopoulos VG, et al. Prediction of respiratory failure in late-preterm infants with respiratory distress at birth. Eur J Pediatr 2011;170(1):45-50.

19. Levit O, Bhandari V, Li FY, Shabanova V, et al. Clinical and laboratory factors that predict death in very low birth weight infants presenting with late-onset sepsis. Pediatr Infect Dis J 2014;33(2):143-6.

20. Richardson DK, Corcoran JD, Escobar GJ, Lee SK. SNAP-II and SNAPPE-II: Simplified newborn illness severity and mortality risk scores. J Pediatr 2001;138(1):92-100.

21. McCormick MC. The contribution of low birth weight to infant mortality and childhood morbidity. $N$ Eng J Med 1985;312(2):82-90.

22. Unterscheider J, O`Donoghue K, Daly S, Geary MP, et al. Fetal growth restriction and the risk of perinatal mortalitycase studies from de multicentre PORTO study. BMC Pregnancy Childbirth 2014;14:63.

23. Alexander GR, de Caunes F, Hulsey TC, Tompkins ME, et al. Validity of postnatal assessments of gestational age: a comparison of the method of Ballard et al. and early ultrasonography. Am J Obstet Gynecol 1992;166(3);891-5.

24. Yau KI, Hsu CH. Factors affecting the mortality of sick newborns admitted to intensive care units. ActaPaedtr Taiwan 1999;40(2):75-82.

25. Horbar JD. A calculator program for determining indices of neonatal respiratory distress syndrome severity. Am J Perinatol 1987;4(1):20-3.

26. Mendoza-Domínguez S, Zavala-Mendoza A, LópezTamanaja NL, Rodríguez-Zepeda JJ, et al. Índices de oxigenación en recién nacidos en estado crítico. Rev Mex Pediatr 1999;66(1):14-7.

27. Varkilova L,Slancheva B,Emilova Z, Nikolov A, etal. Blood lactate measurements as a diagnostic and prognostic tool after birth asphyxia in newborn infants with gestational age $>$ or $=34$ gestational weeks. Akush Ginekol (Sofiia) 2013;52(3):36-43. Bulgaria.

28. Bauman ME, Cheung PY, Massicotte MP. Hemostasis and platelet dysfunction in asphyxiated neonates. J Pediatr 2011;158(2 Suppl):e35-9.

29. Beardsall K, VanhaesebrouckS, Ogilvy-Stuart AL, Vanhole C, et al. Prevalence and determinants of hyperglycemia in very low birth weight infants: cohort analyses of theNIRTURE study. J Pediatr 2010;157(5):715-9.

30. Hirshberg E, Larsen G, Van Duker H. Alterations in glucose homeostasis in the pediatric intensive care unit: Hyperglycemia and glucose variability are associated with increased mortality and morbidity. Pediatr Crit Care Med 2008;9(4):361-6.

31. Apgar V. Infant resuscitation. 1957. Conn Med 2007;71(9):553-5.

32. Baumer JH, Wright D, Mill T. Illness severity measured by CRIB score: a product of changes in perinatal care? Arch Dis Child Fetal Neonatal Ed 1997;77(3):F211-5.

33. Sarquis AL, Miyaki M, Cat MN. Aplicação do escore CRIB para avaliar o risco de mortalidade neonatal. J Pediatr (Rio J) 2002;78(3):225-9.

34. García H, Villegas-Silva R, Villanueva-García D, GonzálezCabello $\mathrm{H}$, et al. Validation of a prognostic index in the critically ill newborn.RevInvestigClin 2000;52(4):406-14.

35. Tavosnanska J, Carreras IM, Fariña D, Luchternberg G, et al. Morbimortalidad de recién nacidos con menos de 1500 gramos asistidos en hospitales públicos de la Ciudad de Buenos Aires. Arch Argent Pediatr 2012;110(5):394-403. 